\title{
The role of disgust propensity and sensitivity on sexual excitation and inhibition in obsessive-compulsive disorder
}

\author{
Andrea Pozza, ${ }^{1}$ Nicole L. Angelo, ${ }^{2}$ Davide Prestia,${ }^{3}$ Davide Dèttore ${ }^{1}$ \\ ${ }^{1}$ Department of Health Sciences, University of Florence, Florence; ${ }^{2}$ School of Psychology, University of Florence, Florence; ${ }^{3}$ Section \\ of Psychiatry, Department of Neuroscience, Rehabilitation, Ophthalmology, Genetics, Maternal and Child Health, University of \\ Genoa, IRCCS San Martino, Genoa, Italy
}

\begin{abstract}
Sexuality is understudied in Obsessive-Compulsive Disorder (OCD). According to the Dual Control Model, low sexual excitation (SE) and high sexual inhibition (SI) are indicative of a higher probability of experiencing a sexual dysfunction. The present study investigated SE and SI in OCD patients compared with controls. It was hypothesized that OCD patients report lower SE and higher SI than controls. Given their potential role as inhibitors of sexual response, it was hypothesized that in the OCD group higher

Correspondence: Andrea Pozza, Department of Health Sciences, University of Florence, via di San Salvi 12, 50135 Florence, Italy. Tel. +39.055.275067 - Fax: +39.055.2751093.

E-mail: andrea.pozza@unifi.it

Citation: Pozza, A., Angelo, N. L., Prestia, D., \& Dèttore, D. (2019). The role of disgust propensity and sensitivity on sexual excitation and inhibition in obsessive-compulsive disorder. Research in Psychotherapy: Psychopathology, Process and Outcome, 22(3), 439-449. doi: 10.4081/ripppo.2019.409

Contributions: AP designed the study, collected the data, conducted the literature searches, conducted the statistical analysis, wrote the first draft of the paper. NLA collected the data, conducted the literature searches, wrote the first draft of the paper. DP collected the data, reviewed the draft of the paper. DD designed the study, reviewed the draft of the paper and checked the editing of the final version of the paper. All authors have approved the final manuscript.

Conflict of interest: the authors declare no potential conflict of interest.

Funding: none. disgust propensity/sensitivity, contamination/washing symptoms, unacceptable thoughts, and obsessive beliefs predicted lower SE, higher SI due to Threat of Performance Failure, and higher SI due to Threat of Performance Consequences. Seventy-two OCD patients and 72 controls matched on gender/age completed the Disgust Propensity and Sensitivity Scale-Revised, Obsessive Beliefs Questionnaire-46, Obsessive Compulsive InventoryRevised, and Sexual Inhibition/Sexual Excitation Scales. OCD patients had higher SE, SI due to Threat of Performance Failure, and SI due to Threat of Performance Consequences than controls. In the OCD group, higher disgust sensitivity, SI due to Threat of Performance Consequences, and perfectionism predicted higher SI due to Threat of Performance Failure. Higher SI due to Threat of Performance Failure and contamination/washing symptoms predicted higher SI due to Threat of Performance Consequences. These findings highlight the presence of sexual difficulties in OCD patients, particularly a higher SE and SI. The latter is especially relevant in those patients with higher disgust sensitivity, contamination/washing symptoms and perfectionism. Psychotherapists should assess and target sexuality during clinicalpractice with OCD patients.
\end{abstract}

Conference presentation: part of this paper was presented at the conference Il disturbo ossessivo compulsivo e la sessualità: intimità tra disgusto e senso di colpa, February 27th, 2019, at the Department of Health Sciences, University of Florence, Italy.

Ethical statement: the authors have abided by the Ethical Principles of Psychologists and Code of Conduct as set out by the American Psychological Association. Institutional Ethical Approval was obtained by the Ethics Committee.

Received for publication: 28 May 2019.

Revision received: 28 August 2019.

Accepted for publication: 29 August 2019.

This work is licensed under a Creative Commons Attribution NonCommercial 4.0 License (CC BY-NC 4.0).

${ }^{\circ}$ Copyright: the Author(s), 2019

Licensee PAGEPress, Italy

Research in Psychotherapy:

Psychopathology, Process and Outcome 2019; 22:439-449

doi:10.4081/ripppo.2019.409
Key words: Obsessive-compulsive disorder; Obsessive beliefs; Disgust sensitivity; Sexual response; Perfectionism.

\section{Introduction}

Sexuality is an important aspect of psychological wellbeing deriving from the interaction of biological, psychological, and social factors that determine an individual's particular sexual behaviour (Stephenson \& Meston, 2015). Various bio-psychosocial factors have the potential to alter sexual encounters and therefore predispose to sexual dysfunctions (SDs) (American Psychiatric Association, 2013). The Dual Control Model (DCM; Janssen \& Bancroft, 2006) was developed as a theoretical framework to assess the probability of experiencing a SD. This model asserts that various 
individual and interpersonal factors determine the predisposition towards Sexual Excitation (SE) or Sexual Inhibition (SI) and therefore to developing sexual problems. According to the DCM, low levels of SE and high levels of SI are indicative of a higher probability of experiencing SDs (Bancroft, Graham, Janssen, \& Sanders, 2009). Janssen, Vorst, Finn, \& Bancroft (2002) expanded the model by introducing two distinct forms of SI: Inhibition Due to Threat of Performance Failure and Inhibition Due to Threat of Performance Consequences (e.g. being seen by others during sexual encounters, contagion with sexually transmitted diseases, undesired pregnancy).

A satisfactory sexual functioning is associated with physical and psychological well-being. It is therefore evident that, in the presence of mental disorders there are higher probabilities of suffering from sexual problems (Waldinger, 2015). Obsessive-Compulsive Disorder (OCD), characterized by obsessions and compulsions, is a mentalcondition that causes significant distress and disability in a variety of quality of life domains (American Psychiatric Association, 2013; Coluccia, Fagiolini, Ferretti, Pozza, \& Goracci, 2015).

According to cognitive behavioural models and a large amount of empirical data,three main types of obsessive beliefs act as maintenance factors of OCD symptoms: i) Overestimation of Threat/Inflated Sense of Responsibility (erroneous beliefs regarding the probability of occurrence of a feared event/one's vulnerability to and critical responsibility for preventing or avoiding negative outcomes); ii) Importance/Control of Thoughts (beliefs that a thought has the same potential as the actual action imagined, that leads the individuals to perceive their thoughts as extremely important, consequently determining thought control strategies to prevent negative events); iii) Perfectionism/Intolerance for Uncertainty (the need to succeed and avoid failure brings OCD patients to set exceedingly high personal standards that are inevitably impossible to meet) (Bouvard, Fournet, Denis, Sixdenier, \& Clark, 2017; Grøtte et al., 2015; Hezel \& McNally, 2016; Miegel, Jelinek, \& Moritz, 2019; Obsessive Compulsive Cognitions Working Group, 2005; Pozza \& Dèttore, 2014; Pozza, Albert, \& Dèttore, 2019; Tolin, Worhunsky, \& Maltby, 2006; Tümkaya, Karadağ, \& Oğuzhanoğlu 2015). Obsessive beliefs are also a target of the psychotherapeutic intervention on OCD (Coradeschi et al., 2012; Pozza, Coradeschi, \& Dèttore, 2013).

Individuals with $\mathrm{OCD}$ frequently experience difficulties regarding sexual desire, arousal, orgasm, and pleasure, potentially as a result of some of the OCD-related characteristics, including contamination/washing symptoms and unacceptable thoughts (pure obsessions) which may interfere with physical contact or sexual fantasies/impulses, respectively (Basson \& Gilks, 2018; Pahwa \& Foley, 2017). In the literature, some studies have investigatedsexual response in OCD patients. Thakurta et al. (2014) found that $53.33 \%$ of OCD patients manifest low desire and arousal, anorgasmia, and avoid sexual encounters. A more recent survey found that $54-73 \%$ of the OCD patientsexperience sexual dissatisfaction, disgust and avoidance, manifest no desire, low levels of arousal, and orgasmic difficulties (Klimowicz, Janicic, \& IsHak, 2017).

Disgust, a universal emotion that motivates to avoid contact with potentially dangerous stimuli, isanother important aspect of the OCD symptomatology (Rozin \& Fallon, 1987), despite is has been found to be related also to other disorders involving contagion such as phobias (e.g. Olatunji, Armstrong, \& Elwood, 2017). In fact, given its protective nature, disgust brings an individual to avoid contact with potential contaminants (e.g. contagious diseases) or with morally/socially repugnant thoughts/impulses/fantasies. Recent neuroimaging studies have provided evidence that similar brain regions (such as the insula and the limbic cortico-striato-thalamo-cortical loop) are implicated in the development and maintenance of OCD and disgust (Knowles, Jessup, \& Olatunji, 2018).

An individual's vulnerability toward this emotional reaction is determined by two factors: Disgust Propensity (DP; frequency and intensity of the emotion) and Disgust Sensitivity (DS; discomfort caused by the emotion) (Bhikram, Abi-Jaoude, \& Sandor, 2017). DP and DS are significantly higher in OCD patients characterized by contamination/washing symptoms, because they perceive themselves as extremely vulnerable and overestimate the possibility and the severity of an eventual contamination (Knowles, Cox, Armstrong, \& Olatunji, 2018). These exaggerated judgments regarding contamination, determine withdrawal and avoidance of certain objects (Zanjani, Yaghubi, Shaiiri, Fata, \& Gholami Fesharaki, 2018) and the need to perform washing compulsions (Melli, Chiorri, Carraresi, Stopani, \& Bulli, 2015). DP and DS may also correlate with OCD symptoms characterized by socially/morally unacceptable thoughts or pure obsessions (Pozza, Mazzoni, Berardi, \& Dèttore, 2016).

DP and DS have been identified as inhibitors of sexual response by the DCM (Bancroft et al., 2009; Janssen \& Bancroft, 2006). Regarding sexual behaviour, this determines fear and avoidance of sexual encounters because of the close contact to bodily fluids or of the probability experiencing unacceptable sexual thoughts/fantasies/impulses (Knowles, Tomarken, \& Olatunji, 2018) and, therefore, a reduction of sexual desire, arousal, and performance. Furthermore, not only does disgust inhibit sexual response (Andrews, Crone, Cholka, Cooper, \& Bridges, 2015), the physiological reactions associated with sexual arousal can provoke those associated with disgust, especially in patients with contamination/washing symptoms (Fleischman, Hamilton, Fessler, \& Meston, 2015).

\section{Rationale and objectives of the present study}

Sexual functioning is an understudied quality of life outcome in OCD and no study investigated sexual 
response according to the DCM, as the few existing studies focused on categorical diagnoses of SDs. In addition, there are no researchdata about the role of OCDrelated factors in sexual responsesuch as obsessive beliefs, DP, DS, and symptom subtypes. Therefore, the present study investigated SE and SI levels in OCD patients compared with controls recruited from the general population. According to the DCM, it was hypothesized that OCD patients report an unbalance between SE and SI, then lower SE and higher SI. Given the role of DP and DS as inhibitors of sexual response according to the DCM, it was also hypothesized that in the OCD group higher DP and DS, higher contamination/washing symptoms, higher unacceptable thoughts (pure obsessions), and higher levels in all the obsessive beliefs were associated with lower SE, with higher SI due to Threat of Performance Failure, and with higher SI due to Threat of Performance Consequences.

\section{Methods}

\section{Inclusion/exclusion criteria}

Inclusion criteria in the clinical group with OCD were i) primary diagnosis of OCD established by a psychiatrist or psychologist through the Structured Clinical Interview for DSM-IV-TR Axis I Disorders (SCID-I; First, Spitzer, Gibbon, \& Williams, 1997), ii) age 18-65 years old, and iii) provision of signed informed consent. Exclusion criteria were i) psychotic disorders, ii) bipolar disorders, iii) mental retardation, iv) neurological diseases, v) OCD induced by drug or medical diseases, vi) active suicidal ideation. The presence of a serotonergic medication was not considered as an exclusion criterion. This choice aimed to warrant the representativeness of our OCD sample relative to the populationof OCD patients routinely accessing mental health centres because this type of medication is the first-line psychopharmacological treatment for OCD and a concurrent serotonergic medication in OCD patients is the rule rather the exception (Pallanti, Grassi, \& Cantisani, 2014). Participants in the clinical group were recruited through mental health specialists at public or private centres. Through a matched case-controlled design, the control group, comprised of individuals recruited from the general population, was created matching each control participant to a clinical participant by gender and age.

\section{Procedure}

Participation was voluntary and uncompensated. All the included participants were asked to provide written informed consent to participate after having received a description of the aims and havinghad the possibility to withdraw consent at any time. Materials containing personal information about participants were kept on electronic supports protected by passwords. The research was conducted according to the Helsinki Declaration and was approved by the Institutional Ethics Committee.

\section{Measures}

\section{Obsessive-Compulsive Inventory - Revised}

The Obsessive-Compulsive Inventory - Revised (OCIR, Foa et al., 2002) is a short version of the Obsessive Compulsive Inventory (OCI; Foa, Kozak, Salkovskis, Coles, \& Amir, 1998) that measures the distress caused by obsessive-compulsive symptoms. Its 18 items are divided into 6 subscales which measure 6 OCD subtypes (Washing, Obsessing, Hoarding, Ordering, Checking and Mental Neutralizing), evaluated using a 5-point Likert scale ( $0=$ Not at all, $4=$ Extremely) (Foa et al., 2002). The Italian version presented good internal consistency $(\alpha>0.70)$, and excellent test-retest reliability $(r>0.70)$ (Sica et al., 2008). In the present study, internal consistency was good for all the subscales.

\section{Disgust Propensity and Sensitivity Scale - Revised}

The Disgust Propensity and Sensitivity Scale - Revised (DPSS-R, van Overveld, de Jong, Peters, Cavanagh, \& Davey, 2006) contains 16 items on a 5-point Likert scale ( $1=$ Never, $5=$ =Always) that evaluate Disgust Propensity and Disgust Sensitivity (van Overveld et al., 2006). In a recent studyon the Italian version using a large clinical sample with OCD patients, the two-factor structure obtained the best fit by confirmatory factor analysis and showed good internal consistency for both the subscales $(\alpha>0.70)$ (Pozza \& Dèttore, submitted; Pozza, Mazzoni, Berardi, \& Dèttore, 2016). In the present study, internal consistency was good for both the subscales.

\section{Obsessive Beliefs Questionnaire - 46}

The Italian version of the Obsessive Beliefs Questionnaire, originally developed by the Obsessive Compulsive Cognitions Working Group (2005), is composed of 46 items that measure 5 types of obsessive beliefs: Perfectionism, Responsibility for Harm, Control of Thoughts, Responsibility for Omissions, and Importance of Thoughts (Dorz, Novara, Pastore, Sica, \& Sanavio, 2009). Each item is evaluated on a 7-point Likert scale (1=Strongly Disagree, 7=Strongly Agree). The Obsessive Beliefs Questionnaire - 46 (OBQ-46, Dorz et al., 2009) presented good internal consistency $(0.65>\alpha>0.86)$ and test-retest reliability $(0.67>\mathrm{r}>0.84)$ (Novara, Dorz, Pastore, Sica, \& Sanavio, 2011). In the present study, internal consistency was good for all the subscales.

\section{Sexual Inhibition/Sexual Excitation Scales}

Developed on the basis of the DCM, the Sexual Inhibition/Sexual Excitation Scales (SIS/SES, Janssen et al., 2002) evaluates individual differences in the sexual response of males (SIS-SES/M) and females (SIS-SES/F) 
using three subscales: Sexual Excitation (SE); Inhibition Due to Threat of Performance Failure (SIS1); Inhibition Due to Threat of Performance Consequences (SIS2). Its 45 items are evaluated on a 4-point Likert scale ( 1 =Strongly Agree, 4=Strongly Disagree); lower scores indicate higher accordance. The original version (Janssen et al., 2002) and the Italian version (Panzeri et al., 2008) of the SIS/SES presented acceptable internal consistency $(0.69>\alpha>0.89)$ and good test-retest reliability $(r>0.60)$. In the present study, internal consistency was good for all the three scales.

\section{Data analysis}

To compare the levels of SE/SI, obsessive compulsive symptoms and beliefs, and DP/DS between the OCD and the control groups, independent samples Student $t$ tests were conducted. In the OCD group, to test the relationship between sexual excitation or inhibition and obsessive compulsive symptoms, obsessive beliefs, and disgust propensity and sensitivity, Pearson's bivariate correlation coefficients were calculated between SIS/SES, OCI-R, OBQ-46, and DPSS-R scores. Correlation coefficient values were interpreted as: $0<r<|0.30|=$ weak, $|0.30|<r<|0.50|=$ moderate, $\quad|0.50|<r< \pm|0.70|=$ strong, $r< \pm|0.70|=$ very strong. To investigate the role of obsessive compulsive symptoms and beliefs and DP/DS on SE/SI, multiple linear regression analyses were conducted in the OCD group by the stepwise procedure, where the scores on the clinical scales which correlated significantly with those on the SIS/SES were included as predictors and SIS/SES scores as outcomes. Statistical analyses were conducted by using SPSS 21.00. Statistical significance was set at a $0.05 \mathrm{P}$-value.

\section{Results}

Socio-demographic and clinical characteristics of the obsessive-compulsive disorder and the control groups

Seventy-two OCD patients and 72 controlswere included. The socio-demographic and the clinical characteristics of the OCD and the control group are provided in Table 1. The OCD group reported significantly higher scores on the OCI-R Total and on all its subscales and on both the DPSS-R Disgust Propensity and the DPSS-R Disgust Sensitivity scalesthan the control group (Table 2).

\section{Comparisons between the obsessive-compulsive disorder and the control groups on sexual excitation/sexual inhibition}

The OCD group reported significantly lower scores on the SE, on the SIS1, and on the SIS2. This result suggested that the OCD group had significantly higher levels of SE, SI due to Threat of Performance Failure, and SI due to Threat of Performance Consequences than the control group (Table 2) .

No significant differences were found on the SIS/SES

Table 1. Socio-demographic and clinical characteristics.

\begin{tabular}{|c|c|c|}
\hline & $\begin{array}{c}\text { OCD group }(n=72) \\
M(S D ; \text { range }) / n(\%)\end{array}$ & $\begin{array}{l}\text { Control group }(n=72) \\
M(S D ; \text { range }) / n(\%)\end{array}$ \\
\hline Age (years) & $34.50(10.39 ; 18-58)$ & $34.25(10.18 ; 18-60)$ \\
\hline \multicolumn{3}{|l|}{ Gender } \\
\hline Female & $27(37.50)$ & $27(37.50)$ \\
\hline Male & $45(62.50)$ & $45(62.50)$ \\
\hline Marital status & & \\
\hline Single & $55(76.40)$ & $42(58.30)$ \\
\hline Married & $15(20.80)$ & $25(34.70)$ \\
\hline Divorced & $2(2.80)$ & $5(7)$ \\
\hline \multicolumn{3}{|l|}{ Education level } \\
\hline Elementary school & $3(4.20)$ & 0 \\
\hline Middle school & $5(6.90)$ & $1(1.40)$ \\
\hline High school & $35(48.60)$ & $32(44.40)$ \\
\hline Degree & $24(33.30)$ & $34(47.20)$ \\
\hline Post-graduate education & $4(5.60)$ & $5(7)$ \\
\hline \multicolumn{3}{|l|}{ Employment status } \\
\hline Undergraduate & $1(1.40)$ & $19(26.40)$ \\
\hline Employed & $16(22.20)$ & $48(66.70)$ \\
\hline Unemployed & $44(61.10)$ & $2(2.80)$ \\
\hline Other & $9(12.50)$ & $3(4.20)$ \\
\hline Age at OCD onset (years) & $21.36(8.90 ; 6-53)$ & \\
\hline Concurrent antidepressant medication & $32(44.40)$ & \\
\hline
\end{tabular}

OCD, obsessive-compulsive disorder. 
scores between the OCD patients who were on serotonergic medications and those who were not. The scores between the two groups were not significantly different on the SE $\left[t_{(70)}=-0.77, \mathrm{P}=0.44\right]$, on the SIS1 $\left[t_{(70)}=-1.13, \mathrm{P}=0.26\right]$, and on the SIS2 $\left[t_{(70)}=-1-03, \mathrm{P}=0.30\right]$.

Association between obsessive compulsive symptoms and beliefs, disgust propensity, disgust sensitivity and sexual excitation/sexual inhibition

In the OCD group, scores on the SEcorrelated positively weakly and significantly only with scores on the OCI-R Total: patients with more intense obsessive compulsive symptoms reported less intense SE.

Scores on the SIS1 correlated negatively weakly and significantly with the scores on the DPSS-R Disgust Propensity and negatively moderately and significantly with the scores on the SIS2, DPSS-R Disgust Sensitivity, OBQ-46 Perfectionism, OBQ-46 Responsibility for Harm, OBQ-46 Responsibility for Omission, OBQ-46 Control of Thoughts: patients with stronger DP and DS, perfectionism, responsibility for harm or omission, control of thoughts and with more intense SI due to Threat of Performance Consequences reported more intense SI due to Threat of Performance Failure.

Scores on the SIS2 correlated negatively weakly and significantly with the scores on the DPSS-R Disgust Propensity, DPSS-R Disgust Sensitivity, OCI-R Checking, and OCI-R Washing: patients with stronger DP and DS, checking and washing symptoms reported more intense SI due to Threat of Performance Consequences. Pearson's bivariate correlation coefficients are provided in Table 3.

Predictive role of obsessive compulsive symptoms and beliefs and disgust propensity/disgust sensitivity on sexual inhibition

The results of the multiple linear regression analyses are provided in Table 4. Only higher scores on the DPSSR Disgust Sensitivity, SIS2, OBQ-46 Perfectionism predicted significantly lower scores on the SIS1. Higher scores on the DPSS-R Disgust Propensity predicted lower scores on the SIS1 at a trend level. The scores on the other clinical scales were not significant predictors of the SIS1 scores. The model explained $40 \%$ of the total variance.

Only scores on the SIS1 and on the OCI-R Washing predicted significantly lower scores on the SIS2. The scores

Table 2. Comparison between the OCD and the control groups on the clinical scales.

\begin{tabular}{|c|c|c|c|c|c|c|c|c|}
\hline & \multicolumn{2}{|c|}{ OCD group $(n=72)$} & \multicolumn{2}{|c|}{ Control group $(n=72)$} & \multirow{3}{*}{$\begin{array}{c}\text { Independent } \\
\text { sample } \\
\text { Student } \\
t \text { test }\left({ }_{d f}\right)\end{array}$} & \multirow{3}{*}{ P-value } & \multirow{2}{*}{\multicolumn{2}{|c|}{$95 \% C I$}} \\
\hline & \multirow[t]{2}{*}{ Mean } & \multirow[t]{2}{*}{$S D$} & \multirow[t]{2}{*}{ Mean } & \multirow[t]{2}{*}{$S D$} & & & & \\
\hline & & & & & & & $\begin{array}{l}\text { Upper } \\
\text { limit }\end{array}$ & $\begin{array}{c}\text { Lower } \\
\text { limit }\end{array}$ \\
\hline SE & 2.58 & 0.54 & 2.87 & 0.43 & $-3.55_{(142)}$ & 0.001 & -0.45 & -0.12 \\
\hline SIS1 & 2.37 & 0.59 & 2.93 & 0.53 & $-5.91_{(142)}$ & $<0.001$ & -0.74 & -0.37 \\
\hline SIS2 & 2.10 & 0.57 & 2.34 & 0.54 & $-2.66_{(142)}$ & 0.009 & -0.43 & -0.06 \\
\hline OCI-R Total & 27.14 & 14.77 & 11.38 & 9.28 & $7.66_{(119,49)}$ & $<0.001$ & 11.69 & 19.83 \\
\hline OCI-R Hoarding & 4.11 & 3.35 & 2.29 & 2.01 & $3.95_{(116.24)}$ & $<0.001$ & 0.90 & 2.73 \\
\hline OCI-R Checking & 5.26 & 3.84 & 1.97 & 2.01 & $6.43_{(106.94)}$ & $<0.001$ & 2.27 & 4.30 \\
\hline OCI-R Ordering & 4.93 & 3.89 & 3.31 & 3.01 & $2.80_{(133.43)}$ & 0.006 & 0.47 & 2.77 \\
\hline OCI-R Obsessing & 6.29 & 3.69 & 1.89 & 2.49 & $8.38_{(124.62)}$ & $<0.001$ & 3.36 & 5.44 \\
\hline OCI-R Neutralizing & 2.39 & 2.57 & 1.30 & 1.72 & $2.95_{(124.04)}$ & 0.004 & 0.35 & 1.80 \\
\hline OCI-R Washing & 4.01 & 3.35 & 1.55 & 2.09 & $5.28_{(119.11)}$ & $<0.001$ & 1.54 & 3.38 \\
\hline DPSS-R Disgust Propensity & 21.90 & 4.82 & 18.53 & 3.85 & $4.63_{(142)}$ & $<0.001$ & 1.93 & 4.81 \\
\hline DPSS-R Disgust Sensitivity & 20.43 & 6.75 & 14.90 & 4.81 & $5.65_{(128.37)}$ & $<0.001$ & 3.59 & 7.46 \\
\hline OBQ-46 Perfectionism & 44.26 & 16.28 & 28.63 & 11.78 & $6.60_{(142)}$ & $<0.001$ & 10.95 & 20.32 \\
\hline OBQ-46 Responsibility for Harm & 44.76 & 14.07 & 34.08 & 11.81 & $4.93_{(142)}$ & $<0.001$ & 6.40 & 14.96 \\
\hline OBQ-46 Control of Thoughts & 45.83 & 17.39 & 31.36 & 13.55 & $5.57_{(133.99)}$ & $<0.001$ & 9.33 & 19.61 \\
\hline OBQ-46 Responsibility for Omission & 23.06 & 10.13 & 14.74 & 6.27 & $5.92_{(118.48)}$ & $<0.001$ & 5.53 & 11.10 \\
\hline OBQ-46 Importance of Thoughts & 21.96 & 11.26 & 13.78 & 5.81 & $5.47_{(106.25)}$ & $<0.001$ & 5.21 & 11.14 \\
\hline
\end{tabular}

OCD, obsessive-compulsive disorder; SE, Sexual Excitation; SIS1, Inhibition Due to Threat of Performance Failure; SIS2, Inhibition Due to Threat of Performance Consequences; OCI-R, Obsessive Compulsive Inventory-Revised; DPSS-R, Disgust Propensity and Sensitivity Scale-Revised; OBQ-46, Obsessive Beliefs Questionnaire-46. 


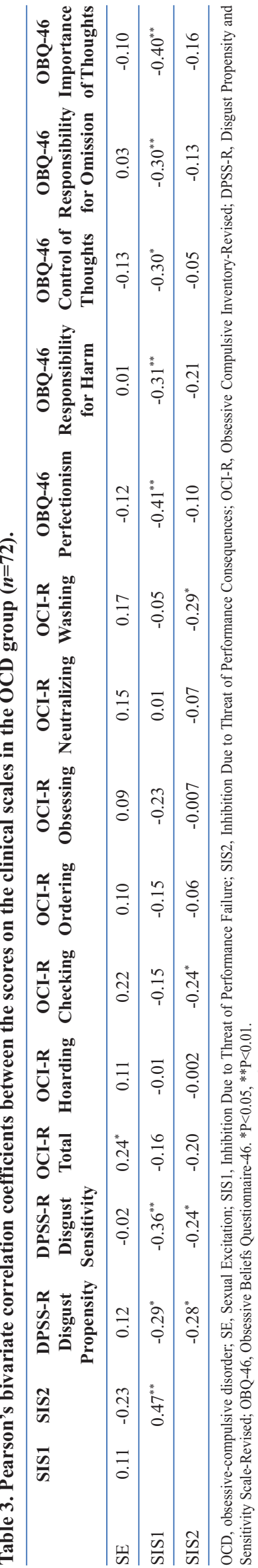

on the other clinical scales were not significant predictors. The model explained $24 \%$ of the total variance.

\section{Discussion}

OCD is a mentalcondition that has a strong impact on a variety of quality of life domains (Coluccia et al., 2016; Pozza, Lochner, Ferretti, Cuomo, \& Coluccia, 2018). Sexual functioning is however understudied by researchers and overlooked by psychotherapists during clinical practice. Some OCD-related factors may be hypothesized to be associated with impaired sexuality. In particular, the frequent/intense disgust reactions, contamination/washing symptoms, unacceptable thoughts and strong obsessive beliefs manifested by these patients might predict worse sexual functioning.

The present study was the first investigation exploring sexual response in OCD patients according to the DCM and the role of OCD-related factors such as obsessive compulsive symptoms and beliefs, DP, and DS. It was hypothesized that OCD patients report an imbalance between SE and SI, then lower SE and higher SI levels than controls. Since DP and DS may inhibit sexual response, according to the DCM it was hypothesized that in the OCD grouphigher DP and DS, higher contamination/washing symptoms, higher unacceptable thoughts (pure obsessions), and higher

Table 4. Regression analyses of SIS/SES scores on OBQ-46, OCI-R, DPSS-R scores in the OCD group $(n=72)$.

\begin{tabular}{lcccc}
\hline Outcome: SIS1 & $\boldsymbol{\beta}$ & $\boldsymbol{t}$ & P-value & Adjusted $\boldsymbol{R}^{\mathbf{2}}$ \\
\hline Constant & & 10.97 & $<0.001$ & 0.40 \\
\hline DPSS-R Disgust Sensitivity & -0.28 & -3.61 & $<0.001$ & \\
\hline SIS2 & 0.39 & 5.95 & $<0.001$ & \\
\hline OBQ-46 Perfectionism & -0.21 & -2.87 & 0.005 & \\
\hline OBQ-46 Responsibility for Harm & 0.10 & 1.09 & 0.27 & \\
\hline OBQ-46 Control of Thoughts & -0.05 & -0.56 & 0.57 & \\
\hline OBQ-46 Responsibility for Omission & -0.06 & -0.62 & 0.53 & \\
\hline OBQ-46 Importance of Thoughts & -0.12 & -1.34 & 0.18 & \\
\hline DPSS-R Disgust Propensity & 0.17 & 1.84 & 0.06 & \\
\hline Outcome: SIS2 & $\boldsymbol{\beta}$ & $\boldsymbol{t}$ & P-value & Adjusted $\boldsymbol{R}^{\mathbf{2}}$ \\
\hline Constant & & 4.95 & $<0.001$ & 0.24 \\
\hline SIS1 & 0.46 & 4.62 & $<0.001$ & \\
\hline OCI-R Washing & -0.27 & -2.68 & 0.009 & \\
\hline OCI-R Checking & -0.12 & -1.21 & 0.22 & \\
\hline DPSS-R Disgust Propensity & -0.01 & -0.03 & 0.97 & \\
\hline DPSS-R Disgust Sensitivity & -0.01 & -0.08 & 0.93 & \\
\hline
\end{tabular}

OCD, obsessive-compulsive disorder; SE, Sexual Excitation; SIS1, Inhibition Due to Threat of Performance Failure; SIS2, Inhibition Due to Threat of Performance Consequences; OCI-R, Obsessive Compulsive Inventory-Revised; DPSS-R, Disgust Propensity and Sensitivity Scale-Revised; OBQ-46, Obsessive Beliefs Questionnaire-46. 
obsessive beliefs are associated with lower SE, with higher SI due to Threat of Performance Failure, and with higher SI due to Threat of Performance Consequences.

The results showed that the OCD group experienced higher levels in all the obsessive compulsive symptoms and obsessive beliefs than the control group, confirming the notion that the obsessive beliefs are associated with OCD. Furthermore, the differences regarding DP and DS showed that OCD patients manifest more frequent/intensedisgust reactions and higher levels of discomfort towards this negative emotion compared to controls.

In contrast with our hypotheses, the OCD group reported a more frequent tendency towards SE than the control group. This result did not seem consistent with the literature data indicating that OCD patients typically manifest no desire of and avoid sexual encounters (Klimowicz et al., 2017; Thakurta et al., 2014) as a result of their thinking style (Real, Montejo, Alonso, \& Mencho, 2013). A higher level of SE in OCD patients than in controls may be the consequence of the avoidance of intimate and sexual relationships which can generally reinforce OCD symptoms through a vicious cycle (Timpano, Çek, Rubenstein, Murphy, \& Schmidt, 2014). It may be speculated that avoidance of interpersonal relations tends to increase SE and also SI. In addition, evidence about $\mathrm{SE}$ in mental disorders is somewhat paradoxical, as not all studies have shown that psychological distress is associated with poorer sexual response. For example, about $20 \%$ of depressed/anxious patients were found to experience increased SE than controls (Janssen \& Bancroft, 2006). Some researchers proposed that increased sexual interest when distressed can be a strategy to cope with loneliness/boredom feelings (Bancroft \& Vukadinovic, 2004). It may also be hypothesized that increased sexual interest emerges in OCD as a means for achieving at least a transient reduction of obsessions. The paradoxical effect of increased SE in the clinical group might be an example of the so-called Excitation Transfer (Zillman, 1983) which occurs when arousal induced in association with anxiety becomes incorporated into response to sexual stimuli. Finally, the evidence of increased SE in OCD may be in line with case reports describing patients whose OCD-related intrusions were accompanied by penis erection (Warwick \& Salkovskis, 1990). Overall, the increased SE in OCD may be the consequence of a dysfunctional imbalance of the sexual response based on the DCM that consists of an increase in both SE and SI.

Consistent with our hypotheses, the present findings showed that OCD patients had higher both SI due to Threat of Performance Failure and SI due to Threat of Performance Consequences. In addition, this result did not seem to be related to the presence of a serotonergic treatment, as OCD patients assuming serotonergic medications did not have different levels of SI than those not assuming them. This result suggests that the psychotherapeutic work with OCD patients should focus also on sexual functioning, particularly SI, and should target fear of performance failure and performance consequences. A potential clinical implication may be the introduction of sex therapy and couple therapy in the standard psychotherapeutic intervention. Indeed, it may be interesting to examine whether the inclusion of sex/couple therapy in the treatment of OCD may improve the outcome of the disorder.

No specific symptom subtypeor obsessive belief was associated with SE in the OCD group. Only higher general OCD symptoms were significantly, yet weakly,associated with lower SE, suggesting that more severe symptoms were associated with lower SE. An explanation of this result might be that patients with more intense symptoms have stronger difficulties being aware of the present moment during sexual interaction due to persisting obsessions and the urge of performing compulsions (Barker, 2017). This result suggests that further research is needed to explore which OCDrelated factors may be associated with a dysfunctional level of SE.

The association between SE and SIsuggeststhat fear of performance failure and fear of performance consequences may be influenced reciprocally: focusing on the performance may compromise the complete involvement in the sexual act, that in turn may lead to thoughts regarding possible negative outcomes, and viceversa.

Higher DS, SI due to Threat of Performance Failure and perfectionism predicted higherSI due to Threat of Performance Consequences. As proposed in Tybur et al.'s model (Tybur, Lieberman, \& Griskevicius, 2009), the three dimensions of disgust (pathogen disgust, sexual disgust, and moral disgust), are finalized to protect individuals from potential contaminating stimuli. This being said, the association observed suggests that disgustreactions may lead to avoiding sexual stimuli for fear of contamination through contact with specific body parts and fluids (Tybur, Lieberman, Kurzban, \& DeScioli, 2013), and may bring the individual to negatively evaluate the sexual act in itself (de Jong, van Overveld, \& Borg, 2013), but also the various physiological sensations associated with sexual arousal (Knowles, Borg, \& Olatunji, 2017). In other words, disgusting sexual stimuli may predispose to performance difficulties and lead to focalize on potential negative consequences. This also explains the association between SI due to Threat of Performance Consequences and contamination/washing symptoms: washers patientswould report more frequent sexual difficulties due to the possible consequences of the sexual encounter, for example contracting a sexually transmitted disease (Knowles, Tomarken, \& Olatunji, 2018).

Our data suggest also that perfectionism plays an important role in SI: polarizing attention exclusively 
towards intrusive thoughts, and consequently ignoring sexual sensations, might hinder excitation (Klimowicz et al., 2017). In fact, the egodystonicity of sexual intrusive thoughts (evaluated negatively and catastrophized) brings the individual to constantly check his/her genitals for signs of sexual arousal in potentially inappropriate situations (Vella-Zarb, Cohen, McCabe, \& Rowa, 2017) or control/suppress the unwanted thoughts (Moulding, Aardema, \& O'Connor, 2014). In addition, perfectionism may lead the individual to try to meet unrelenting standards during the sexual act that in turn inhibit sexual response.

Finally, SI due to performance failure seems to be determined by the fear of potentially dangerous consequences, the need to meet excessively high standards, and DS. This last aspect meets the aim of our study to identify the disgust dimensions responsible for SI in OCD. The role of DS in SI due to performance failure can be explained by considering the importance of the insula. For example, this structure regulates the emotion of disgust and its subsequent subjective evaluation during exposure to disgusting stimuli (Knowles, Jessup, \& Olatunji, 2018) so as to render said stimuli salient. However, this structure is also important during sexual arousal (Murphy, Brewer, Catmur, \& Bird, 2017); therefore, during intimate relations the individual tends to focus on these salient aspects causing performance failure. This in turn, determines the tendency towards perfectionism, inevitably leading to more errors and therefore causing performance failure.

No disgust dimensionswere predictive of SI due to Threat of Performance Consequences which was mostly associated with SI due to Threat of Performance Failure and contamination/washing symptoms. In this case, fear of contamination might motivate to avoid/prevent transmission of pathogens through activation of washing compulsions.

Finally, the current study has some strengths. The results contribute to expand the scarce literature on sexual functioning in OCD patients, in that they underline the OCD-related factors associated with specific impaired sexual tendencies. Furthermore, these results suggest some implications for clinical practice. Specifically, in light of these findings, practitioners should strive to implement integrated and individualized treatments that consider the ways in which disgust dimensions are associated with sexual behaviour in OCD patients, in so facilitating treatment and promoting quality of life.

It is also necessary to take into consideration some limitations. Firstly, the sole use of self-report questionnaires poses a methodological limitation. Future research should use psychophysiologicaland/or interview-based measures of sexual response. Secondly, the cross-sectional design does not allow a causal link between OCD and impaired sexual response to be ascertained. In addition, the lack of another clinical group does not allow us to distinguish completely the effects of OCD-related factors from the non-specific effects of distress related to having a mental problem. Future studies may use also a clinical group,for example including patients with anxiety disorders or patients with other obsessive-compulsive spectrum conditions (e.g., body focused repetitive disorders) (Pozza, Giaquinta, \& Dèttore, 2016).

Another aspect which is worthy of investigation is whether the association between OCD and impaired sexual functioning is predictive of major psychopathological disorders (e.g., psychosis). In particular, previous literature showed that certain OCD dimensions (i.e., sexual and aggressive obsessions) are associated with psychotic symptoms (DeVylder et al., 2012; Tolin, Abramowitz, Kozak, \& Foa, 2001). It may be interesting to investigate whether the association between these specific OCD dimensions and impaired sexuality is predictive of psychotic symptoms or disorders.

\section{Conclusions}

The present study is the first investigation exploring sexual functioning in OCD patients according to the DCM and examining the role of some OCD-related factors such as obsessive compulsive subtypes and beliefs, DP and DS. The findings highlight the presence of sexual difficulties in OCD patients, particularly higher tendencies towards SE and SI than controls. SI tendencies are especially relevant in those patients with contamination/washing symptoms, higher perfectionism, and DS. In conclusion, these findings offer a new perspective on the assessment and the psychotherapeutic work with OCD patients, extending the focus of clinical practice to a broader set of quality of life outcomes.

\section{References}

American Psychiatric Association. (2013). Diagnostic and statistical manual of mental disorders (5th ed.). Washington, DC: American Psychiatric Association.

Andrews, A.R., Crone, T., Cholka, C.B., Cooper, T.V., \& Bridges, A.J. (2015). Correlational and experimental analyses of the relation between disgust and sexual arousal. Motivation and Emotion, 39, 766-779. doi: 10.1007/s11031-015-9485-y

Bancroft, J., Graham, C. A., Janssen, E., \& Sanders, S. (2009). The dual control model: Current status and future directions. Journal of Sex Research, 46, 121-142. doi: 10.1080/00224490902747222

Bancroft, J., \& Vukadinovic, Z. (2004). Sexual addiction, sexual compulsivity, sexual impulsivity, or what? Toward a theoretical model. Journal of Sex Research, 41, 225-234. doi: 10.1080/00224490409552230

Barker, M. J. (2017). Mindfulness in sex therapy. In Z.D. 
Peterson (Ed.), The Wiley Handbook of Sex Therapy (pp. 435-452). Chichester: John Wiley \& Sons Ltd.

Basson, R., \& Gilks, T. (2018). Women's sexual dysfunction associated with psychiatric disorders and their treatment. Women's Health, 1, 1-16. doi: 10.1177/1745506518762664

Bhikram, T., Abi-Jaoude, E., \& Sandor, P. (2017). OCD: obsessive-compulsive ... disgust? The role of disgust in obsessive-compulsive disorder. Journal of Psychiatry \& Neuroscience, 42, 300-306. doi: 10.1503/jpn.160079

Bouvard, M., Fournet, N., Denis, A., Sixdenier, A., \& Clark, D. (2017). Intrusive thoughts in patients with obsessive compulsive disorder and non-clinical participants: a comparison using the International Intrusive Thought Interview Schedule. Cognitive Behaviour Therapy, 46, 287-299. doi: 10.1080/16506073.2016.1262894

Coluccia, A., Fagiolini, A., Ferretti, F., Pozza, A., Costoloni, G., Bolognesi, S., \& Goracci, A. (2016). Adult obsessivecompulsive disorder and quality of life outcomes: a systematic review and meta-analysis. Asian Journal of Psychiatry, 22, 41-52. doi: 10.1016/j.ajp.2016.02.001

Coluccia, A., Fagiolini, A., Ferretti, F., Pozza, A., \& Goracci, A. (2015). Obsessive-Compulsive Disorder and quality of life outcomes: protocol for a systematic review and metaanalysis of cross-sectional case-control studies. Epidemiology, Biostatistics and Public Health, 12, 2. doi: $10.2427 / 10037$

Coradeschi, D., Pozza, A., Mannelli, E., Mengoli, G., Rotundo, L., Neri, T., \& Dèttore, D. (2012). Obsessive belief changes in patients with resistant ocd treated daily with prolonged exposure and response prevention. Psicoterapia Cognitiva e Comportamentale, 18, 23-37.

de Jong, P.J., van Overveld, M., \& Borg, C. (2013). Giving into arousal or staying stuck in disgust? Disgust-based mechanisms in sex and sexual dysfunction. Annual Review of Sex Research, 50, 247-262. doi: 10.1080/00224499. 2012.746280

DeVylder, J. E., Oh, A. J., Ben-David, S., Azimov, N., Harkavy-Friedman, J. M., \& Corcoran, C. M. (2012). Obsessive compulsive symptoms in individuals at clinical risk for psychosis: association with depressive symptoms and suicidal ideation. Schizophrenia Research, 140, 110113. doi: 10.1016/j.schres.2012.07.009

Dorz, S., Novara, C., Pastore, M., Sica, C., \& Sanavio, E. (2009). Presentazione della versione italiana dell'Obsessive Beliefs Questionnaire (OBQ): struttura fattoriale e analisi di attendibilità (parte I). Psicoterapia Cognitiva e Comportamentale, 15, 139-170.

First, M. B., Spitzer, R., Gibbon, M., \& Williams, J. (1997). Structured Clinical Interview for DSM-IV Axis I Disorders (SCID-I). Firenze: Giunti OS.

Fleischman, D.S., Hamilton, L.D., Fessler, D.M., \& Meston, C.M. (2015). Disgust versus Lust: Exploring the interactions of Disgust and Fear with Sexual Arousal in Women. PLoS ONE, $10 . \quad$ doi: 10.1371/journal.pone.0118151

Foa, E.B., Huppert, J.D., Leiberg, S., Langner, R., Kichic, R., Hajcak, G., et al. (2002). The Obsessive-Compulsive Inventory: Development and Validation of a Short Version. Psychological Assessment, 14, 485-496. doi: 10.1037//1040-3590.14.4.485

Foa, E. B., Kozak, M. J., Salkovskis, P. M., Coles, M. E., \& Amir, N. (1998). The validation of a new obsessivecompulsive disorder scale: The Obsessive-Compulsive
Inventory. Psychological Assessment, 10, 206-214. doi: 10.1037/1040-3590.10.3.206

Grøtte, T., Solem, S., Vogel, P. A., Güzey, I. C., Hansen, B., \& Myers, S. G. (2015). Metacognition, responsibility, and perfectionism in obsessive-compulsive disorder. Cognitive Therapy and Research, 39, 41-50. doi: 10.1007/s10608014-9635-7

Hezel, D. M., \& McNally, R. J. (2016). A theoretical review of cognitive biases and deficits in obsessive-compulsive disorder. Biological Psychology, 121, 221-232. doi: 10.1016/j.biopsycho.2015.10.012

Janssen, E., \& Bancroft, J. (2006). The dual control model: the role of sexual inhibition \& excitation in sexual arousal and behavior. The Psychophysiology of Sex. Bloomington: Indiana University Press.

Janssen, Vorst, H., Finn, P., \& Bancroft, J. (2002). The sexual inhibition (SIS) and sexual excitation (SES) scales: I. Measuring sexual inhibition and excitation proneness in men. Journal of Sex Research, 39, 114-126. doi: 10.1080/00224490209552130

Klimowicz, A., Janicic, A., \& IsHak, W.W. (2017). Sex and Chronic Psychiatric Illness. In W.W. IsHak (Ed.), The Textbook of Clinical Sexual Medicine (pp. 507-524). Switzerland: Springer International.

Knowles, A.K., Borg, C., \& Olatunji, B.O. (2017). Disgust, Disease, and Disorder: Impurity as a Mechanism for Psychopathology. In R. Duschinsky, S. Schnall \& D. Weiss (Eds.), Purity and Danger Now: New Perspectives ( $1^{\text {st }}$ ed., pp. 103-132). Abingdon, Oxon; New York, NY: Routledge.

Knowles, K. A., Cox, R. C., Armstrong, T., \& Olatunji, B. O. (2018). Cognitive mechanisms of disgust in the development and maintenance of psychopathology: A qualitative review and synthesis. Clinical Psychology Review, 69, 30-50. doi: 10.1016/j.cpr.2018.06.002

Knowles, K.A., Jessup, S.C., \& Olatunji, B.O. (2018). Disgust in Anxiety and Obsessive-Compulsive Disorders: Recent Findings and Future Directions. Current Psychiatric Reports, 20, 67-76. doi: 10.1007/s11920-018-0936-5

Knowles, K.A., Tomarken, A.J., \& Olatunji, B.O. (2018). Effects of exposure to erotica on disgust: A preliminary test among contamination-fearful individuals. Journal of Obsessive-Compulsive and Related Disorders, 18, 54-60. doi: 10.1016/j.jocrd.2018.06.006

Melli, G., Chiorri, C., Carraresi, C., Stopani, E., \& Bulli, F. (2015). The two dimensions of contamination fear in obsessive-compulsive disorder: Harm avoidance and disgust avoidance. Journal of Obsessive-Compulsive and Related Disorders, 6, 124-131. doi: 10.1016/j.jocrd.2015.07.001

Miegel, F., Jelinek, L., \& Moritz, S. (2019). Dysfunctional beliefs in patients with obsessive-compulsive disorder and depression as assessed with the Beliefs Questionnaire (BQ). Psychiatry Research, 272, 265-274. doi: 10.1016/j.psychres. 2018.12.070

Moulding, R., Aardema, F., \& O’Connor, K. P. (2014). Repugnant obsessions: A review of the phenomenology, theoretical models, and treatment of sexual and aggressive obsessional themes in OCD. Journal of ObsessiveCompulsive and Related Disorders, 3, 161-168. doi: 10.1016/j.jocrd.2013.11.006

Murphy, J., Brewer, R., Catmur, C., \& Bird, G. (2017). Interoception and psychopathology: A developmental neuroscience perspective. Developmental Cognitive 
Neuroscience, 23, 45-56. doi: 10.1016/j.dcn.2016.12.006

Novara, C., Dorz, S., Pastore, M., Sica, C., \& Sanavio, E. (2011). Presentazione della versione italiana dell'Obsessive Beliefs Questionnaire (parte II). Validità convergente e specificità dei costrutti in un campione clinico. Psicoterapia Cognitiva e Comportamentale, 17, 157-172.

Obsessive Compulsive Cognitions Working Group (2005). Psychometric validation of the obsessive belief questionnaire and interpretation of intrusions inventoryPart 2: Factor analyses and testing of a brief version. Behaviour Research and Therapy, 43, 1527-1542. doi: 10.1016/j.brat.2004.07.010

Olatunji, B. O., Armstrong, T., \& Elwood, L. (2017). Is disgust proneness associated with anxiety and related disorders? A qualitative review and meta-analysis of group comparison and correlational studies. Perspectives on Psychological Science, 12, 613-648. doi: 10.1177/1745691616688879

Pahwa, P.K., \& Foley, S.M. (2017). Biopsychosocial Evaluation of Sexual Dysfunctions. In W.W. IsHak (Ed.), The Textbook of Clinical Sexual Medicine (pp. 79-94). Switzerland: Springer International.

Pallanti, S., Grassi, G., \& Cantisani, A. (2014). Emerging drugs to treat obsessive-compulsive disorder. Expert Opinion on Emerging Drugs, 19, 67-77. doi: $10.1517 / 14728214.2014 .875157$

Panzeri, M., Dèttore, D., Altoe, G., Zanella, F., Baldetti, M., \& Janssen, E. (2008). T01-O-14 Factor structure of the Italian Sexual Inhibition/Excitation (SIS/SES) scales. Sexologies, 17, S54. doi: 10.1016/S1158-1360(08)726641

Pozza, A., Albert, U., \& Dèttore, D. (2019). Perfectionism and intolerance of uncertainty are predictors of OCD symptoms in children and early adolescents: a prospective, cohort, one-year, follow-up study. Clinical Neuropsychiatry, 16, 53-61.

Pozza, A., Coradeschi, D., \& Dèttore, D. (2013). Do dysfunctional beliefs moderate the negative influence of comorbid severe depression on outcome of residential treatment for refractory OCD? A pilot study. Clinical Neuropsychiatry, 10, 72-83.

Pozza, A., \& Dèttore, D. (2014). Are inflated responsibility beliefs specific to OCD? Meta-analysis of the relations of responsibility to OCD, anxiety disorders, and depression symptoms. Clinical Neuropsychiatry, 11, 170-181.

Pozza, A., \& Dèttore, D. (submitted). Confirmatory factor structure of the Italian Disgust Propensity and Sensitivity Scale-Revised (DPSS-R) in a clinical sample with obsessive-compulsive disorder.

Pozza, A., Giaquinta, N., \& Dèttore, D. (2016). Borderline, avoidant, sadistic personality traits and emotion dysregulation predict different pathological skin picking subtypes in a community sample. Neuropsychiatric Disease and Treatment, 12, 1861. doi: 10.2147/NDT.S109162

Pozza, A., Lochner, C., Ferretti, F., Cuomo, A., \& Coluccia, A. (2018). Does higher severity really correlate with a worse quality of life in obsessive-compulsive disorder? A metaregression. Neuropsychiatric Disease and Treatment, 14, 1013. doi: 10.2147/NDT.S157125

Pozza, A., Mazzoni, G.P., Berardi, D., \& Dèttore, D. (2016). Studio preliminare sulle proprietà psicometriche della versione italiana della Disgust Propensity and Sensitivity Scale - Revised (DPSS-R) in campioni non-clinici e campioni clinici con Disturbo Ossessivo-Compulsivo e Disturbi d'ansia. Psicoterapia Cognitiva $e$ Comportamentale, 22, 271-296.

Real, E., Montejo, A., Alonso, P., \& Mencho, J.M. (2013). Sexuality and obsessive-compulsive disorder: the hidden affair. Neuropsychiatry, 3, 23-31. doi: 10.2217/NPY.12.7

Rozin, P., \& Fallon, A. E. (1987). A Perspective on Disgust. Psychological Review, 94, 23-41. doi: 10.1037/0033295X.94.1.23

Sica, C., Ghisi, M., Altoè, G., Chiri, L.R., Franceschini, S., Coradeschi, D., \& Melli, G. (2008). The Italian version of the Obsessive Compulsive Inventory: Its psychometric properties on community and clinical samples. Journal of Anxiety Disorders, 23, 204-211. doi: 10.1016/j.janxdis.2008.07.001

Stephenson, K. R., \& Meston, C. M. (2015). The conditional importance of sex: exploring the association between sexual well-being and life satisfaction. Journal of Sex \& Marital Therapy, 41, 25-38. doi: 10.1080/0092623X.2013.811450

Thakurta, R.G., Singh, O.P., Dhar, P., Sarkar, S., Ray, P., \& Mallick, A.K. (2014). Prevalence and nature of sexual dysfunctions in OCD in a tertiary medical college. Eastern Journal of Psychiatry, 17, 20-30.

Timpano, K. R., Çek, D., Rubenstein, L. M., Murphy, D., \& Schmidt, N. B. (2014). Exploring the association between obsessive-compulsive symptoms and loneliness: Consideration of specificity and gender. Journal of Cognitive Psychotherapy, 28, 264-273. doi: 10.1891/08898391.28.4.264

Tolin, D. F., Abramowitz, J. S., Kozak, M. J., \& Foa, E. B. (2001). Fixity of belief, perceptual aberration, and magical ideation in obsessive-compulsive disorder. Journal of Anxiety Disorders, 15, 501-510. doi: 10.1016/S08876185(01)00078-0

Tolin, D. F., Worhunsky, P., \& Maltby, N. (2006). Are "obsessive" beliefs specific to OCD?: A comparison across anxiety disorders. Behaviour Research and Therapy, 44, 469-480. doi: 10.1016/j.brat.2005.03.007

Tümkaya, S., Karadağ, F., \& Oğuzhanoğlu, N. K. (2015). Relationship between obsessive beliefs and symptoms in patients with obsessive compulsive disorder. Nöro Psikiyatri Arşivi, 52, 54-58. doi: 10.5152/npa.2015.7015

Tybur, J. M., Lieberman, D., \& Griskevicius, V. (2009). Microbes, Mating and Morality: Individual differences in three functional domains of disgust. Journal of Personality and Social Psychology, 97, 103-122. doi: 10.1037/a0015474

Tybur, J. M., Lieberman, D., Kurzban, R., \& DeScioli, P. (2013). Disgust: Evolved function and structure. Psychological Review, 120, 65-84. doi: 10.1037/a0030778

Van Overveld, W.J.M., de Jong, P.J., Peters, M.L., Cavanagh, K., \& Davey, G.C.L. (2006). Disgust propensity and disgust sensitivity: Separate constructs that are differently related to specific fears. Personality and Individual Differences, 41, 1241-1252. doi: 6/j.paid.2006.04.021

Vella-Zarb, R.A., Cohen, J.N., McCabe, R.E., \& Rowa, K. (2017). Differentiating Sexual Thoughts in ObsessiveCompulsive Disorder From Paraphilias and Nonparaphilic Sexual Disorders. Cognitive and Behavioral Practice, 24, 342-352. doi: 10.1016/j.cbpra.2016.06.007 
Waldinger, M. D. (2015). Psychiatric disorders and sexual dysfunction. Handbook of Clinical Neurology, 130, 469489. doi: 10.1016/B978-0-444-63247-0.00027-4

Warwick, H.M., \& Salkovskis, P.M. (1990). Hypochondriasis. Behaviour research and therapy, 28, 105-117. doi: 10.1016/0005-7967(90)90023-c

Zanjani, A., Yaghubi, H., Shaiiri, M., Fata, L., \& Gholami Fesharaki, M. (2018). Relationship between disgust propensity and contamination obsessive-compulsive symptoms: The mediating role of information processing bias. Iranian Red Crescent Medical Journal, 20, 11. doi: 10.5812/ircmj. 67133

Zillman, D. (1983). Transfer of Excitation in Emotional Behavior. In J.T. Cacioppo, R.E. Petty (Eds.), Handbook of Social Psychology (pp. 215-230). New York: Guilford Press. 